\title{
Human Resource and Nuclear Knowledge Management-Pakistan’s Scenario
}

\author{
Syed Javaid Khurshid \\ Centre for International Strategic Studies, Islamabad, Pakistan
}

\begin{abstract}
Nuclear knowledge management integration has become very important in the current nuclear sector scenario of Pakistan. Pakistan Atomic Energy came into being in 1956 and large scale human resource was hired in 1957 and in 1973 to implement the program of peaceful uses of energy. The appropriate human resource consisting of appropriate scientist \& engineers than hired and trained from the best laboratories of USA and UK has now been retired leaving a knowledge gap. Simultaneously on the other side the Civil Nuclear Power Program of Pakistan is expanding tremendously and PAEC the only organization has to fulfill its first target of 8,800 MW of nuclear energy by 2030 and of 40,000 MW by 2050. Besides having five power reactors producing 1,335 MWe, Pakistan is building three 1,000 MW reactors, 02 at Karachi, 01 at Chashma, and planned 02 at Mufargrah. This increasing civil nuclear power program requires skilled and trained human resource for the nuclear cycle, management of ageing nuclear installations and their safely decommissioning. There is a dire need of effective and efficient institutional memory for these new nuclear power projects, their efficient operation, environmental remediation around them and implementation of nuclear safety regulations. Scientists and engineers should be able to communicate effectively to promote understanding, its wider relevance and to encourage more informed decision making at all levels. The increased scientific knowledge among masses will result in effective sustainable development. Pakistan Nuclear Society feels that its mandate has to manage and disseminate nuclear knowledge in the scientific community, politicians, and public to develop confidence in the practices and safety procedures of the nuclear program.
\end{abstract}

Keywords: nuclear power, nuclear knowledge management, Pakistan

\section{Introduction}

Pakistan is in energy crises since its independence which has been aggravated with the time and start effecting badly since 2006; it happened due to in adequate addition of energy production sources and non-exploitation of hydro, coal, and renewable potential of the country. This situation has led to a continuous demand and supply gap which has increased by the time and ultimately resulted in load shedding of gas and electricity. This demand keeps on increasing and now this demand supply gap is more than 3,000 in winters where it reaches 5,000 to 7,500 MW in summer season as the requirement increases from 23,000 to 28,000 MW. This is putting a tremendous pressure on Pakistan to exploit indigenous resources such as hydro, coal, and

Syed Javaid Khurshid, Ph.D., Dr., distinguished visiting fellow, Centre for International Strategic Studies, Islamabad, Pakistan.

Correspondence concerning this article should be addressed to Syed Javaid Khurshid, Centre for International Strategic studies, Suite 506, 5th Floor Evacuee Trust, G-5/1, Agha Khan Road, Islamabad, Pakistan. 
nuclear to achieve sustainable development goals set in vision 2050. At present the Pakistan Energy Mix is oil (29\%), hydel (19\%), gas (28\%), nuclear (5\%), and others 1\%. Pakistan has to increase the share of its nuclear power from $5 \%$ to at least $15 \%$, for this, government has given a target to Pakistan Atomic Energy of 8,800 MW by 2030 and 40,000 MW up to 2050 (Ministry of Planning, Development \& Reforms, Planning Commission, Pakistan Annual Report, 2017).

\section{Nuclear Power Program}

The first nuclear body Pakistan Atomic Energy came into being in 1956 and large scale recruitment is done in 1957 to begin the program and in 1973 to implement the program in different fields. The first generation of the scientist \& engineers hired than and trained from the best laboratories of USA and UK has now been retired and now the second generation hired in 1974 is retiring, leaving a knowledge gap in the field of nuclear science. Second, the Civil Nuclear Program in Pakistan is expanding tremendously as PAEC has to fulfill the given target. At present PAEC is running five Nuclear Power Plants, one $95 \mathrm{MW}$ at Karachi by the name of Karachi Nuclear Power Plant (KANUPP-1 or K-1) established in 1992, four of 325 MW each, Chashma Nuclear Power Plant-1 (CHASHMA-1 or C-1), since 2000, Chashma Nuclear Power Plant-2 (CHASMA-2 or C-2) since 2011, Chashma Nuclear Power Plant-3 (CHASHMA-3 or C-3) since 2016, and Chashma Nuclear Power Plant-4 (CHASHMA-4 or C-4) since April 2017, providing a total of 1,335 MWe (World Nuclear Association Report, 2018). The two Power Plants of 1,000 MW are under construction at KANUPP, Karachi with the assistance of Chinese. These Power Plants are expected to be completed in 2019 and 2020 respectively. The eighth Power Plant Chashma-5 (C-5) of 1,000 MW is also in starting process, whereas proposal of other Power Plant is under process and survey; land study and land acquisition is under process to achieve the target set by the government of 40,000 MW by 2050 .

The above mentioned upcoming Civil Nuclear Power Program needs a strong infrastructure backing and engineering support. There is lack of international standard engineering support in the private sector in the country. This has pressed hard PAEC to establish international standard infrastructure and workshops of its own to support its Civil Nuclear Power Program. There are now many workshops being developed and working to their full strength, a mechanical workshop by the name of SES for precision engineering; the other one is Heavy Mechanical Complex (HMC-3) which is involved in designing, manufacturing heavy equipment for chemical and nuclear power plants. All this equipment is manufactured according to the relevant international codes and standards and following all the guidelines and safety rules and regulation which are developed by the national regulatory authority Pakistan Nuclear Regulatory Authority (PNRA).

\section{Human Resource for Nuclear Power Program}

To support this Civil Nuclear Power Program, the target oriented research and development in the field of Nuclear Science and Technology and in allied fields of Physics and Chemistry is in progress. The Pakistan Institute of Nuclear Science and Technology (PINSTECH) is concentrating on the peaceful utilization of nuclear technology. It is a premier institute of science and technology carrying out basic research in the applied and required fields. Over the years this institutes have developed itself in a hub for training of manpower and providing scientific background to PAEC program. The institute carries out basic research in required fields. It also helps PAEC programs such as production of radioisotopes for its 18 cancer hospitals. It has state of art machines under one roof and contributes a lot to preparing manpower and support to PAEC projects. The 
institute has a 5 MW swimming pool type of research reactor (PARR-1) which has been upgraded to $10 \mathrm{MW}$ the experience obtained in upgradation of designing and engineering and renovation was very beneficial. This experience has developed a confidence and self-reliance in the engineers for the future work. This institute has another research reactor of 27 MW (PARR-2). These reactors are used for teaching and training, production of radioisotopes and for neutron activation analysis (Pakistan Atomic Energy Commission, Pakistan, Annual Report, 2015).

Pakistan Atomic Energy has given great emphasis on the peaceful uses of nuclear technology since its inception. In agriculture nuclear technology is used to develop new crop varieties with new traits such as increase productivity, pest control, water management. So far in last 53 years about 94 varieties of different crops have been developed by three agricultures and o1 biotechnology institutes which are now covering about $35 \%$ of crop area throughout Pakistan. PAEC is also a pioneer to introduce saline agriculture technology in the country and transferred to other nine-member state of IAEA. These nuclear agriculture institutes are working on food decontamination to increase their shelf life. Due to their efforts a food irradiator has been installed in Lahore. These institutes are also playing very important role in developing know how, transferring knowledge, and introducing new agriculture techniques to the farmers of the country.

As discussed, Pakistan has given great emphasis to another peaceful use of nuclear technology using it for medical purposes. At present, 34 nuclear medicine and radiotherapy facilities are working in the country, whereas, 18 are regulated by PAEC in the country. These institutes have state of art machines such as dual head Gamma cameras and PET cameras for diagnosis and CO-60 and Linear accelerators for treatment. These Nuclear Medicine Institutes are regulating Cancer Registry Program and treating about 1,250,000 patients/year. These institutes are involved in Cancer awareness, prevention and teaching and training program. The doctors are trained in FCPS, DMRT, and MS in nuclear medicine and radiotherapy (Pakistan Atomic Energy Commission, Pakistan, Annual Report, 2015).

We all know that Pakistan as developing country, at present has a very small nuclear technology base compared to developed countries. Nuclear Knowledge Management has become very important for nuclear sector of Pakistan, as all the critical points to increase Nuclear Knowledge Management are applicable to the current scenario of Pakistan. The increasing development program requires skilled and trained manpower and needs an effective Nuclear Knowledge Management of the whole nuclear cycle, management of ageing nuclear installations and their safely decommissioning. The projected annual requirements for new nuclear scientists and engineers over the years will challenge existing academic and training institutions. Additionally, the nuclear academic workforce may need to increase to meet the demand for educating/training of the new workforce. For this specific training programs has been enhanced and many specific institutes have been developed, fully equipped with latest and state of the art facilities, aiming to provide high quality education and training to its workforce. The following institutes not only provide human resource but also contribute towards science communication, nuclear knowledge management, and Research \& Development (R\&D) programs of Pakistan.

Pakistan Institute of Engineering \& Applied Sciences (PIEAS) is among the best education institute of in HEC ranking. PIEAS offers MS and Ph.D. programs in Nuclear Engineering, Systems Engineering, Physics, Nuclear Medicine, Radiation Medical Oncology, Mechanical Engineering, Process Engineering, Materials Engineering, and Medical Physic, as well as M. Phil in physics and computer sciences. At undergraduate level it offers BS programs in Electrical Engineering and Mechanical Engineering. Karachi Institute of Power 
Engineering (KINPOE)'s main task is to develop human resource in the field of Nuclear Power Technology for which it provides education and training to scientists, engineers, and technicians. KINPOE offers Master's Program in Nuclear Power Engineering, Post Graduate Training Program (PGTP), and Post Diploma Training program (PDTP) every year. Chashma Centre of Nuclear Training (CHASCENT) primarily focuses on training of fresh engineers/technicians and is also involved in Certification/Licensing of plant personnel. CHASCENT offers Probabilistic Safety Assessment (PSA) and Self-Assessment \& Performance Analysis (SA\&PA) programs for power plants.

In teaching and training Agriculture and Biotechnology Institutes are also playing very important role by arranging training courses, workshops, seminars, and conferences. They arrange about 45 courses every year for hands-on training of latest techniques and technologies in various fields of agriculture to benefit farmers, scholars, students, and from various research organizations and universities. They are affiliated with PIEAS for award of degrees (Pakistan Atomic Energy Commission, Pakistan, Annual Report, 2016).

PAEC besides making a strong Nuclear Knowledge Base has also adopted different methods to avoid knowledge gap by retaining of highly trained \& important manpower after the age of 60 as advisors and consultant and appointing the highly technical manpower on contract basis even after 65 as consultants.

There is a dire need of communication and managing nuclear knowledge for these new development projects, efficient operation of new power plants, environmental remediation around them and implementation of nuclear safety regulations; it needs maximum local participation with effective and efficient institutional memory. Pakistan Nuclear Society, a nonprofit organization, having about 3,000 nuclear scientist and engineers as members, feels that according to its mandate, it has to disseminate and manage nuclear knowledge in the scientific community as well as in the public at large to develop confidence in the practices and safety procedures of the nuclear program. Beside highly trained scientists and engineers, Pakistan is fortunate enough to have world largest young population in of the age of 18-35 and it's very important to train this valuable wealth on Nuclear Energy Cycle at different universities.

Centre for International Strategic Studies and Pakistan Nuclear Society (Seminar on "Nuclear Energy Scenario of Pakistan”, 2016) increasingly realizes that Pakistan should conduct and respectively implement Nuclear Energy Program in the country and that is only possible if the citizens understand and support the program. PNS feels that it has to develop Nuclear Knowledge Management, a better communication \& understanding of the public on the nuclear energy issues such as radioactive protection, radioactive waste management and environment.

\section{References}

Annual Report. (2017). Ministry of Planning. Development \& Reforms, Planning Commission, Pakistan.

Pakistan Vision 2025-Executive Summary. (2015). Ministry of Planning, Development and Reforms. Islamabad, Pakistan.

Pakistan Atomic Energy Commission, Annual Report. (2015). Islamabad, Pakistan.

Pakistan Atomic Energy Commission, Annual Report. (2016). Islamabad, Pakistan.

Seminar on "Nuclear Energy Scenario of Pakistan”. (2016). Pakistan Nuclear Society. Retrieved from website: www.pns.org

World Nuclear Energy Association, Report. (2018). 